\title{
Research of High Voltage Intelligent Capacitor
}

\author{
Yang Minxiang, Song Wei, Zhao Xuesong \\ Jiebei Electric Power Maintenance Company \\ Beijing, China \\ ymx142622@163.com
}

\author{
Liu Yang \\ State Grid Material Limited Company \\ Beijing, China
}

\author{
Zhang Guoliang, Diao Yanping, Mao Ting \\ Jiebei Electric Power Maintenance Company \\ Beijing, China
}

\begin{abstract}
In order to develop intelligent capacitor for improving intelligent level of the capacitor, intelligent capacitor's structure and sensors are studied in this paper. By designing external sensors and monitor scheme, intelligent capacitor with external sensor is developed. By designing built-in sensor and their overall arrangement, intelligent capacitor with built-in sensor is developed. Researches show that intelligent capacitors with external sensor adapt to the transform of old capacitors and intelligent capacitors with built-in sensor adapt to new building of capacitor platform. External sensor method can only monitor a string of capacitors, locating fault capacitor need a small amount of tests no power. Built-in sensor design can accurately monitor one capacitor's capacitance and internal temperature.
\end{abstract}

Keywords-intelligent capacitor; sensor; structural characteristics; intelligent power grid technology

\section{INTRODUCTION}

In high voltage substation, because of high voltage level, the height of the capacitor platform usually in a few meters or even more than ten meters above the earth. Which makes operation personnel in equipment maintenance process is hard to find the phenomenon of capacitor shell cracking, capacitor swelling, impregnant outside leakage, and so on, and also can't monitor the temperature change, the electric capacitance change and insulation decline of the single capacitor. It makes the safety and stability of the capacitor and the reliable operations of the power system have a great hidden trouble.

In conventional maintenance strategy of high voltage capacitor, the following ways are widespread used. When a capacitor set trip out, the maintenance personnel test capacity of each single capacitor. The routine maintenance strategy is a fault diagnosis way afterwards, unable to real-time online monitoring and anticipates capacitor fault trend.

In order to improve the intelligence operation level of the capacitor, foreign research institutions such as ABB, NOKIAN, CEPRI have developed a lot of research, but mainly forced in the secondary system[1]-[2], the research of the capacitor itself involved rarely; Chinese and foreign scholars have carried out a lot of research relate to substation intelligent technology[3]-[7], but the research of capacitor intelligent mainly focus on low voltage capacitor field, and some products come out[8], the research of high voltage capacitor intelligence has just started.

Because of capacitor's compact structure, and limited wireless space outside of the capacitors put into operation, the structure research of the capacitor is a basic study in the research of intelligent capacitor. 


\section{MONITORING PRINCIPLE OF INTELLIGENT CAPACITOR \\ ONLINE}

According to the current monitoring methods, capacitors electric capacity test is a mature technology [9]. Real-time monitoring of single capacitor's electric capacity is very useful for maintain personnel to judge the running situation of capacitor, therefore, through the electric capacity online testing realize capacitor online monitoring is the development direction of the intelligent capacitor.

The principle of electric capacity testing is

$$
\mathrm{I}=\omega \mathrm{CU}
$$

When some AC voltage is put at both ends of the capacitors, using clamp ampere ammeter measure current through capacitor, under the circumstances of voltage and frequency are not invariable, the capacity and current direct proportion. So with a scale conversion, the capacitance can be showed in the test instrument.

Based on the above principle, intelligent capacitor through capturing the running voltage, current, and grid frequency makes on-line monitoring to be realization. The research of intelligent capacitor structure will be based on these aspects.

\section{DESIGN WAY WITH EXTERNAL SENSOR}

Capturing the running voltage and current of capacitor, need to choose reasonable data capture methods, and to design the reasonable capture device structure and installation position. Considering the intelligent transformation of existing capacitor, the design way with external sensor is studied firstly.

\section{A. Design of CT}

The basic structure of capacitor is shown in Fig1. In order to facilitate the installation, CT is cross-core structure, which is installed in the bottom of the capacitor's casing, as shown in Fig2.

There are two types of cross-core CT including passive type and active type. Active type CT has high accuracy, which is generally better than 0.2 levels. The capacitance error caused by it is about $0.4 \%$ most. Passive type CT's accuracy is range from 0.5 magnitudes to several levels.
The capacitance error caused by it is about $1 \%$ most. Both of them can meet requirements of capacitor detection: 3\%. But active type CT needs external DC power supply, in order to simplifying obtaining power device, passive type CT with 0.5 magnitudes is chosen

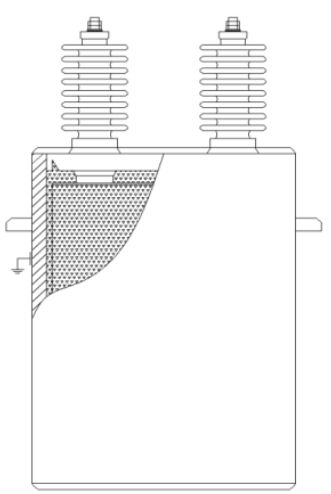

Fig1、Structure of the Capacitor

For a few capacitors which series operate, installing one CT on only one of them can realize the monitoring to anyone.

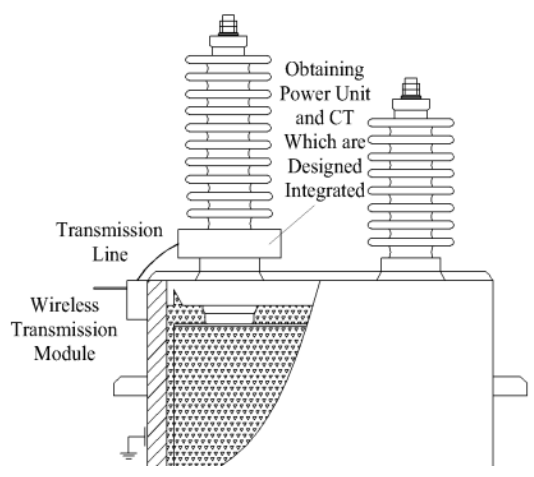

Fig2、Intelligent Capacitor with External Sensor

\section{B. Design of PT}

It is almost impossible to install a PT at the exit of the high voltage bushing for the reason that the size of high voltage PT is large, while the capacitor set is impact. According to the structure of capacitors installed, only one PT used for measuring the voltage of the capacitors string should be installed on each bridge of the arm. In this way, the total electric capacity of a string should be calculated and judged whether changed. So the scope of off-line testing and inspection should be narrowed.

The theoretical basis of monitoring electric capacity of a capacitor string can find the electric capacity change of 
one capacitor is that when the capacitors in series, its total electric capacity $\mathrm{C}$ is

$$
\mathrm{C}=\frac{1}{\frac{1}{\mathrm{C}_{1}}+\frac{1}{\mathrm{C}_{2}}++\frac{1}{\mathrm{C}_{\mathrm{n}}}}
$$

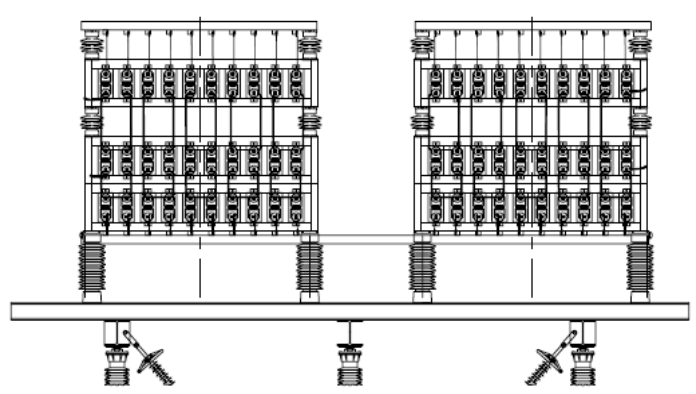

Fig3、Assembly Structure of High Voltage Series of Capacitors

The total capacity is less than anyone capacitor. When the electric capacity of one of the capacitors lessen, the total electric capacity must be reduced, and vice versa. So that it can tell the electric capacity of one of the capacitors has changed.

\section{Data transmission design}

Intelligent capacitors transform is based on the existing capacitor. Therefore, using wireless transmission is undoubtedly the most intelligent, the most efficient, and cost of minimum way.

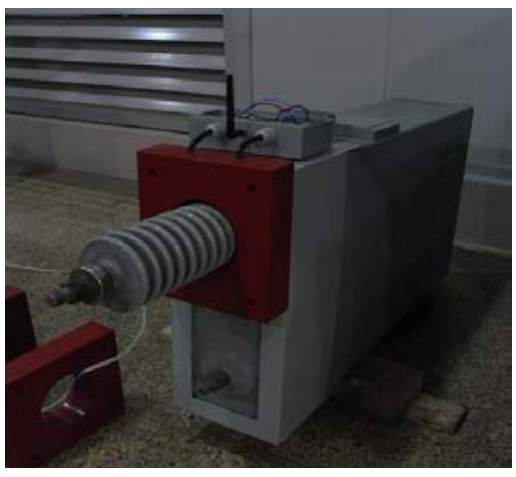

Fig4、Real Figure of Intelligent Capacitor with External Sensor

Using wireless transmission way, the obtaining power method of wireless transmission module should be considered. PT measure voltage signal at the both ends of the single bridge of the arm. The power for voltage signal wireless transmission module is achieved by an obtaining power coil designed in PT. This is the way of voltage obtaining power. The power for current signal wireless transmission module could be achieved by the way of current obtaining power. In order to reduce the effect of obtaining power unit to the insulation of high voltage capacitor casing, obtaining power unit and CT are designed integrated. The real figure is shown in Fig4.

\section{DESIGN WAY WITH BUILT-IN SENSOR}

For the new intelligent capacitor series compensation devices, using built-in sensor is considered. This section research the overall design scheme of capacitor with built-in sensor.

\section{A. Technical requirements of sensor used in the capacitor}

Because of internal compact structure of capacitor, and abominable running conditions, under the precondition that not changing the shape and structure of the capacitor, sensor used for intelligent capacitor need to meet the following requirements:

- Size of sensor cannot be too big;

- Sensor and internal insulating medium are incompatible with each other;

- Sensor can work normally in the capacitor;

- Design of sensor signals’ out method is reliable to not influence explosion resistance performance of capacitor shell.

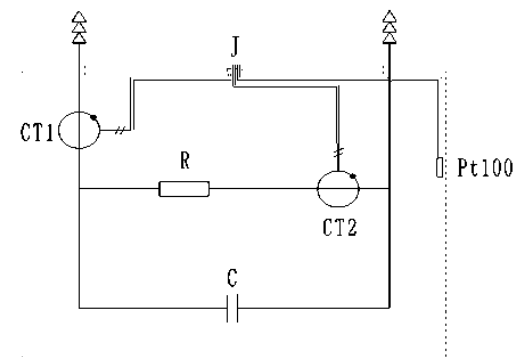

Fig5、Measuring Principle Diagram of Intelligent Capacitor with built-in Sensor

CT1-CT for capacitor; CT2-CT for sampling resistance; C-capacity of capacitor; R-sampling resistance; Pt100-platinum thermistor; J-electric connector; dotted line-capacitor shell

\section{B. Design of CT}

In the capacitor, there is usually a space about dozens of mm high between the core and capacitor's box cover. This position can just be used to install CT. CT is set on 
the outline of the capacitor, and fixed in the capacitor. We have designed CT made by the stainless steel shell, and filled by silica gel, which can incompatible with impregnant. At the same time, in order to meet the requirement of insulating properties, root lengthened casing, which can increase creepage distance, is used, as shown in Fig6.

\section{Design of PT}

Conventional electromagnetic style PT, due to huge volume, can't be embedded into the capacitor, while smaller hall transformer can't meet the requirements of the insulation performance. Therefore, in this paper, parallel precision resistor between the both poles of the capacitor is used. Measuring loop current by current transducer to indirect measure the capacitor voltage, as shown in Fig6.

Sampling resistance should be able to achieve enough sampling accuracy, but not increase the loss of the capacitor significantly. If the sampling resister is chose appropriately, it can be used for sampling and charging. In this study, HTE type high voltage precision no-inductance resistance is chosen, its power-environment temperature curve is shown in Fig7. When the environment temperature is $125^{\circ} \mathrm{C}$ below, the power loss is the same, which perfectly suited to the operation environment of the capacitor.

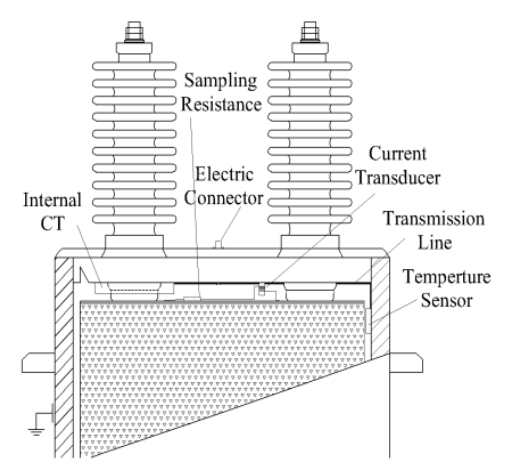

Fig6、Intelligent Capacitor with Built-in Sensor

\section{The Design of Temperature Sensor}

The type of running environment temperature of the capacitor is $-45 / \mathrm{C}$. To products temperature categories is $\mathrm{C}$, the highest temperature is $50^{\circ} \mathrm{C}$. When the product is running under rated voltage, the temperature of most hottest coil is about $10^{\circ} \mathrm{C}$ high than external environment temperature. So in theory, the operating temperature of the sensor range from $-45^{\circ} \mathrm{C}$ to $60{ }^{\circ} \mathrm{C}$ can meet the requirements. Due to the requirements of the product manufacturing process and that operation voltage may have certain range of fluctuations, and sensor itself exists within the scope of error, so increasing the sensor's working temperature range is appropriate. According to the operation experience of the capacitor, working temperature range from $-50^{\circ} \mathrm{C}$ to $80^{\circ} \mathrm{C}$ will be able to satisfy most conditions.

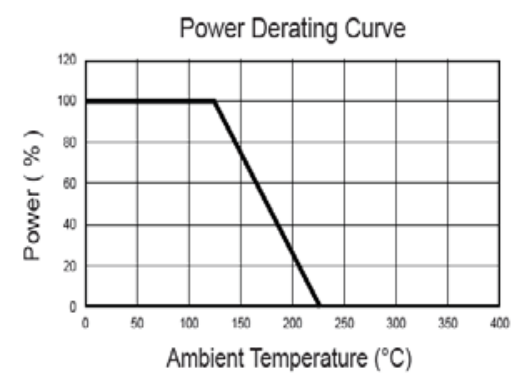

Fig7、 Power-Environment Temperature Curve of THE Type High Voltage Precision Noninductive Resistance

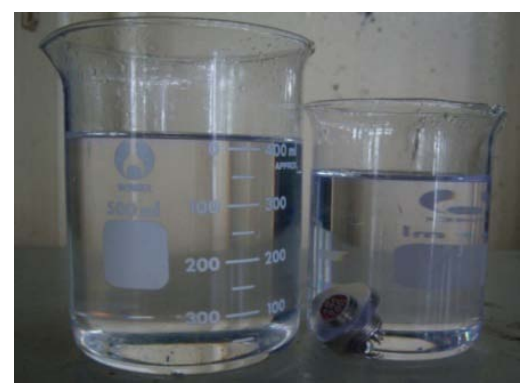

Fig8、Compatibility Experiment of Electric Connector

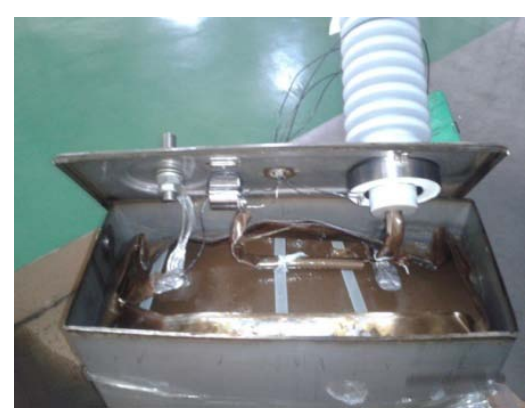

Fig9、Real Figure of Intelligent Capacitor with Built-in Sensor

Based on the above requirements, platinum thermistor is used for measuring the temperature. Resistance of platinum thermistor changes with temperature, it can be used to measure the temperature within the scope of $-200^{\circ} \mathrm{C}$ to $650{ }^{\circ} \mathrm{C}$, its advantage is stable electrical performance 
and high precision, meanwhile, temperature and resistance are linear relationship nearly ${ }^{[10]}$.

\section{E. Data transmission design}

Intelligent capacitor's sensors are all built-in. The collected date should be transmitted to outside. In this research, electric connector is used to send data out. Conventional electric connector is filled by plastic which cannot satisfy the requirement of compatibility. So we have designed the electric connector filled by glass sintering insulators. According to military standard, shell of the electric connector has reached the requirement of explosion resistance performance. Compatibility experiment of electric connector is shown in Fig8. Real figure of intelligent capacitor with built-in sensor is shown in Fig9.

\section{CONCLUSION AND QUESTION ANALYSIS}

\section{A. Conclusion}

- Intelligent capacitor transformation method using external sensors and using built-in sensors are studied.

- Results of this paper can realize real-time online monitoring and fault diagnosis of capacitor's capacitance.

- External sensor method can only monitor a string of capacitors, locating fault capacitor need a small amount of tests no power.

- Built-in sensor design can accurately monitor one capacitor's capacitance and internal temperature.

\section{B. Question analysis}

- Due to the increased length of capacitor casing, the area of the capacitor platform will increase. So the insulating properties of intelligent capacitors need to be studied continually, to choose the bushing with appropriate length.

- Whether the temperature sensor can reflect internal average temperature of the capacitor is not clear, the effect of temperature sensor's location to temperature monitoring need to be studied continually.

\section{REFERENCES}

[1] Michael C. Kleman. "Capacitor Bank Protection and Automati c Control Using the Type DPU2000R Intelligent Electronic D evice,” Apr. 1997, pp. 1-4. http://www.google.com.hk/url?sa=t \&rct $=\mathrm{j} \& \mathrm{q}=$ intelligent + capacitor $+\mathrm{ABB} \&$ source $=$ web\&cd $=5 \&$ ved $=$ 0CHIQFjAE\&url=http\%3A\%2F\%2Fwww.electricalmanuals.net\% 2Ffiles\%2FRELAYS\%2FABB\%2FDPU\%2FAN-33-97.pdf\&ei=D XbXT5LsA4-ziQeLzaz9Ag\&usg=AFQjCNHollMt3jY-1SP05rw7 vav215fyAQ\&cad=rjt

[2] ABB Company. "Capacitors and Filters Improving power qual ity for efficiency and reliability,” 2010, pp. 1-23. http://www. google.com.hk/url?sa=t\&rct=j\&q=intelligent+capacitor+ABB\&so urce=web\&cd=4\&ved=0CG4QFjAD\&url=http $\% 3 \mathrm{~A} \% 2 \mathrm{~F} \% 2 \mathrm{Fww}$ w05.abb.com\%2Fglobal\%2Fscot\%2Fscot245.nsf\%2Fveritydisplay\% 2F29b24f474aa7e4e4c12577e50057910c\%2F\%24file\%2Fabb_1hs m954331-01_capacitors_and_filters_en.pdf\&ei=DXbXT5LsA4-zi QeLzaz9Ag\&usg=AFQjCNGQ1Myi0PkXAw48aaPQhV5hkhBs_ g\&cad=rjt

[3] WU Zhongliang, "Progress of the On-line Monitoring Technique of a High Voltage Breaker,” Electric Switchgear, vol. 1, Jan. 2011, pp. 1-3, 6 .

[4] WANG Hairong, XU Yang, ZHAO Jun-lei. “On-line Monitoring and Fault Diagnosis of SF6 Circuit Breakers Based on Gas State Analysis,” vol. 3, Mar. 2011, pp. 44-47.

[5] WANG Fuyong, FANG Ruiming, CHEN Huagui. "Electrical contacts heat of outdoor high-voltage isolators and monitoring on-line,” vol. 10, May. 2011, pp. 135-139.

[6] TANG Lin, WANG Baoshan, XIONG Yi, etc. "Online Monitor System of Digital AC UHV Sur ge Arrester,” vol. 35, Nov. 2009, pp. 2624-2628.

[7] LI Sinan, LIU Li, LIU Yan, etc. "Design of Sensor of Arrester On-line Monitoring Based on ZigBee Wireless Network,” vol. 24 Apr. 2011. Pp.69-70.

[8] HU Guofu, GUO Xiaoli. "Research on Multi-path Cascade Compensation Intelligent Capacitors,” Vol. 32, Aug. 2011, pp. 38-41, 47.

[9] DANG Xiaoqiang, LIU Nian. "Online monitoring technology research of capacitor,” vol. 6, May. 2003, pp. 6-7,55

[10] Building Automation Products, Inc. "Temperature Accuracy of Thermistors and RTDs,” Mar. 2008. http://www.google.com.h $\mathrm{k} / \mathrm{url}$ ?sa=t\&rct=j\&q=platinum+thermistor\&source=web\&cd=10\& ved=0CK4BEBYwCQ\&url=http\%3A\%2F\%2Fwww.bapihvac.co m\%2Fcontent\%2Fuploads\%2F2010\%2F07\%2FRTD-vs-Thermist ors.pdf\&ei=-X3XT5eYHYSYiAe_9eGRAw\&usg=AFQjCNFhI1P fr4Fv3VY08k9eLge_4lRarQ\&cad=rjt 